\title{
The Kirkendall Effect in Diffusion of Aluminum into $\alpha$-Iron
}

\author{
By Kôsaburô Satố*
}

\begin{abstract}
The Kirkendall effect was observed for diffusion of aluminum into $\alpha$-iron. An iron polycrystal block with W-markers was sealed together with $\mathrm{Fe}_{3} \mathrm{Al}$ powder in an iron-cylinder and was subjected to diffusion anneal. The marker shift was found to proportionate with the square root of annealing period, but no porosity was found near the marker. The chemical diffusion coefficient for aluminum into iron was obtained as a function of aluminum concentration by Matano's analysis. Diffusion coefficients of iron and aluminum at the position of marker were also calculated by narker velocity $\boldsymbol{v}_{m}$ and the chemical diffusion equation by Darken, and also by the ratio of diffusive quantities of iron and aluminum at the position of marker and Darken's equation. These two values are in good agreement in order of magnitude.
\end{abstract}

$$
\text { (Recuived March 25, 1963) }
$$

\section{Introduction}

Since mass flow in the case of intermetallic diffusion, namely the Kirkendall effect, was observed at first in the Cu-Zn system(1) ${ }^{(1)}$ f.c.c. structure, this effect has been observed in various binary systems of f.c.c. structure by several authors(2) (12).

Based on theoretical calculations ${ }^{(13) \sim(17)}$ and experiments mentioned above, it has been comfirmed that the vacancy lattice diffusion mechanism prevails in the f.c.c. binary system.

In b.c.c. metals, however, there has been no theoretical calculation enough to decide whether perfect lattice diffusion or imperfect lattice diffusion actually takes place. With alkali metals Paneth(18) suggested crowd-ion diffusion mechanism, while Fumi(19) proposed vacancy diffusion mechanism and Zener $^{(20)}$ and LeClaire(21) the possibility of ring diffusion mechanism.

To observe the mass flow in b.c.c. under these circumstances is of importance to make clear the diffusion mechanism in b.c.c. lattice. Recently the Kirkendall effect has been observed in b.c.c. lattice ( $\mathrm{Ti}-\mathrm{Mo}^{(22)}$, $\mathrm{Zn}-\beta$ brass $\left.^{(11)}, \mathrm{U}-\mathrm{Zr}^{(23)}, \mathrm{K}-\mathrm{Rb}^{(24)}, \mathrm{Fe}^{(\mathrm{Cr}}{ }^{(25)}\right)$. To obtain further information for this effect in b.c.c.

* Faculty of Literature and Science, Hirosaki University, Hirosaki.

(1) E. O. Kirkendall and A. D. Smigelskas: Trans. AIME, 171 (1947), 120.

(2) L. C. Correa daSilva and R. F. Mehl : Trans. AIME, 191 (1951), 155.

(3) H. Buckle and J. Blin : J. Inst. Metals, 80 (1951-52), 885.

(4) R. S. Barnes : Proc. Phys. Soc., Bj5 (1952), 572 ; Phil. Mag., (7) 43 (1952), 1221.

(5) W. Seith and A. Kottmann : Naturwiss., 39 (2) (1952), 40.

(6) W. Seith and A. Kottmann: Angewandte Chemie, 64 (4) (1952), 371.

(7) H. W. Mead and C. E. Birchenall : Trans. AIME, 2C9 (1957), 874.

(8) T. Heumann and G. G. Walther: Z. Metallk., 48(1957), 157.

(9) J. R. Manning: Phys. Rev. in press.

(10) R. S. Barnes and D. J. Mazey: Acta, Met., 6 (1958), 121.

(11) R. W. Balluffi and B. H. Alexander : J. Apple. Phys., 23 (1953), 953 ; J. Metals, 4 (1952), 1315.

(12) T. Heumann and A. Kottmann: Z. Metallk., 44 (1953), 139.

(13) H. B. Huntington and F. Seitz: Phys. Rev., 61 (1942), 315. lattice in this paper, an attempt has been made to observe the Kirkendall effect in the b.c.c. region of Al-Fe system.

\section{Experimental Procedure and Results}

The experimental data on the Kirkendall effect in b.c.c. structure are very few as compared with those in f.c.c. This is because of the limitations in selecting the material.

In the present experiment $\alpha$-iron was made into solid phase and aluminum into vapour phase. Making use of the diffusion between vapor and solid phases (26) (29), the Kirkendall effect in Al-Fe system has been investigated.

The concentration of $\mathrm{Al}$ atoms diffused in a specimen of $\alpha-\mathrm{Fe}$ under a partial pressure of $\mathrm{Al}$ at a given temperature was determined by X-ray analysis of the lattice constant. The atmosphere of $\mathrm{Al}$ was produced from an appropriate and constant amount of $\mathrm{Fe}_{3} \mathrm{Al}$ powder which was sealed together with the $\alpha$-Fe specimen in an evacuated quartz capsule. The lattice constant of quenched specimens of $\mathrm{Fe}-\mathrm{Al}$ system. is

(14) H. B. Huntington: Phys. Rev., 61 (1942), 325.

(15) H. B. Huntington and Seitz: Phys. Rev., 76 (1949), 1728.

(16) F. G. Fumi : Phil. Mag., 46 (1955), 1007.

(17) A. Zeener: Acta. Cryst., 3 (1950), 346.

(18) H. R. Paneth: Phys. Rev., 80 (1956), 708.

(19) F. G. Fumi: Phil. Mag., 46 (1955), 1007.

(20) C. Zener : Acta. Cryst., 3 (1950), 346.

(21) A. D. Leclaire: Acta. Met., 1 (1953), 438.

(22) P. G. Shewmon and J. H. Pohteld: Acta Met., 2 (1955), 577.

(23) Y. Adda, J. Philbert and H. Fraagi : Rev. de Metallugie, 54 (1957), 577.

(24) L. Yang, M. T. Simnad and R. F. Mehl: Trans. AIME, 212 (1958), 412.

(25) H. W. Paxton and E. J. Parsiers: Trans. AIME, 218 (1960), 794.

(26) R. W. Balluffi and B. H. Alexander : J. App. Phys., 23 (1952), 953.

(27) R. W. Balluffi and B. H. Alexander : J. App. Phys., 23 (1952), 1237

(28) R. W. Balluffi and B. H. Alexander : J. Metals, 4 (1952), 1315.

(29) R. W. Balluffi and L. L. Seigle: J. App. Phys, 25 (1945), 607. 
related monotonously with the concentration of $\mathrm{Al}$ below 25 at \%(30). The reason for using of $\mathrm{Fe}_{3} \mathrm{Al}$ as a source of the vapor phase of $\mathrm{Al}$ is to restrict the concentration of $\mathrm{Al}$ in the specimen below the above critical concentration.

Electrolytic iron (99.9\%) was used as the solvent metal, which was melted in vacuum and being after cold worked, cut into a block of the size $5 \times 10 \times 15 \mathrm{~mm}^{3}$ as shown in Fig. 1. The possible mechanical strain due

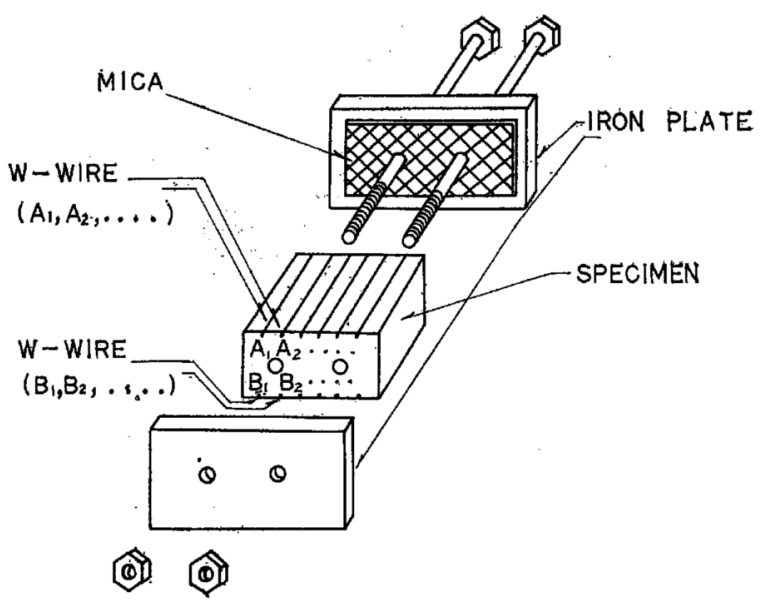

Fig. 1 Detail of the specimen used.

to working process was released by annealing (at $800^{\circ} \mathrm{C}$ for $2 \mathrm{hr}$ ) in vacuum. After winding $\mathrm{W}$ wire $(0.02 \mathrm{~mm} \phi)$ around the block, it was put between two tempered steel plates $\left(3 \times 4 \times 1.5 \mathrm{~cm}^{3}\right)$ and pressed (about $2 \sim 3 \mathrm{t} / \mathrm{cm}^{2}$ ) with an oil-compresser to bury the $\mathrm{W}$ wire into it. The excess wire was then removed. The final form of the specimen used is shown in Fig. 1.

As shown in the figure, the distances between centers of wires $A_{1}$ and $B_{1}, A_{2}$ and $B_{2}$, and so on were first measured with a comparator (accuracy $1 / 1000 \mathrm{~mm}$ ) and the mean values were taken as the distance between markers. The cut surfaces were pressed with two pieces of mica and iron plate (about $2 \mathrm{~mm}$ thick) to prevent vaporization of $\mathrm{Al}$ on the cut surfaces. In this case, care was given lest the $\mathrm{W}$ wire shloud leave the surfaces by pressing.

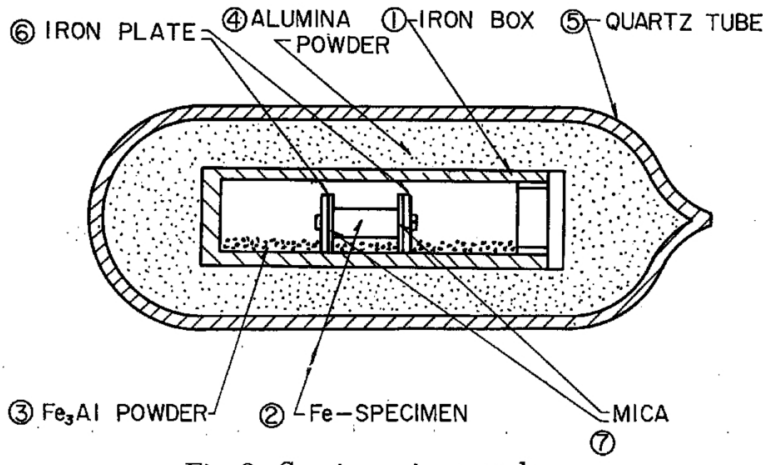

Fig. 2 Specimen in capsule.

$\mathrm{Fe}_{3} \mathrm{Al}$ dust (200 mesh) (3) was put together with specimen (2) in an iron cylinder (1) as in the Fig. 2. The cylinder was put together with alumina powder

(30) W. B. Pearson : A Handbook of Lattice Spacing and Structure of Metal and Alloys Pergamon Press 4 and 5 Fitzroy Square London, W. 1 (1958), 344.
(4) in a quartz tube (5), which was then evacuated and sealed. Alumina powder serves to prevent the reaction between iron cylinder and quartz tube.

The raw materials for $\mathrm{Fe}_{3} \mathrm{Al}$ dust were $99.98 \% \mathrm{Fe}$ and $99.99 \% \mathrm{Al}$. The temperature of diffusion annealing was $850 \pm 4{ }^{\circ} \mathrm{C}$ and the annealing period was between 400 and $1600 \mathrm{hr}$. The specimen was heated or cooled rapidly at the beginning and end of annealing. After annealing, the specimen was taken out from the

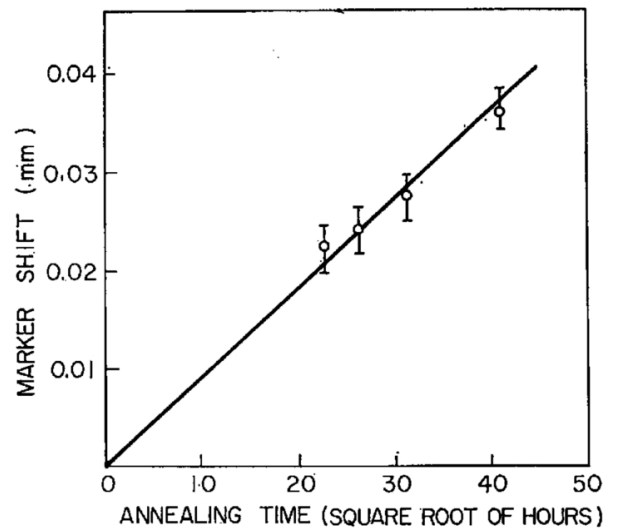

Fig. 3 Relation between marker shift and square root of annealing time.

iron cylinder and the distances between the upper $\left(A_{1}, A_{2}, \cdots\right)$ and lower $\left(B_{1} B_{2}, \cdots\right) W$ wires were measured with a comparater. The distance between W-markers was found to increase during the annealing. As shown in Fig. 3 the increase in distance, namely the marker shift $x$ is proportional to the square root of the the annealing time.

The surface of the specimen was also examined by a microscope after polishing, but no porosity was found around the markers.

Next the diffused surface was dipped in nitric acid solution (about $20 \%$ ) and corroded it in etching by about $1 / 100 \mathrm{~mm}$. Then the lattice constant of the etched surface was measured by the back reflected focusing method. The concentration of $\mathrm{Al}$ contained in the iron block was thus determined from a known relation ${ }^{(30)}$ between $\mathrm{Al}$ concentration and lattice constant in the Fe-Al system. A typical example of

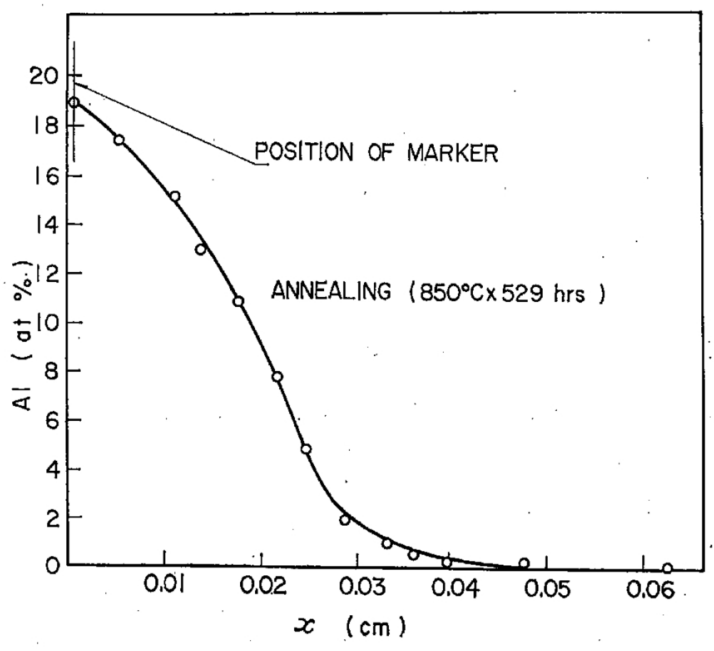

Fig. 4 Relation between penetration depth and concentration of $\mathrm{Al}$, 
the results is shown in Fig. 4. In all specimens, the concentration of $\mathrm{Al}$ at the surface was about 19 at \% and that at the marker position about 18.8 at $\%$. It should be noted that the diffusion, therefore, took place in b.c.c. lattice and the concentration at the surface was independent of diffusion time.

Although the lattice constant increases with the increasing $\mathrm{Al}$ concentration, the effect of lattice expansion upon the avarage penetration distance is estimated under $10 \%$ of the marker shift and is negligible compared to the marker movement. Consequently it appears that the marker movement is mainly due to the Kirkendall effect.

\section{Discussion}

From the present measurements it may be said that the experimental condition of a constant vapour pressure in the vapour phase is approximately satisfied, because the concentration of $\mathrm{Al}$ at the surface of the specimens was independent of the period of diffusion and this fact shows that the partial pressure of $\mathrm{Al}$ vaporized from $\mathrm{Fe}_{3} \mathrm{Al}$ powder should reach a constant value in the relatively early stage.

The marker shift is proportional to the square root of annealing period. This relation is consistent with the formula proposed by daSilva and Mehl(31) on the f.c.c. system, and Landergren ${ }^{(32)}$ on the b.c.c. system; thus

$$
x=B \sqrt{t} \exp (-A / R T),
$$

where $A$ and $B$ are constants independent of temperature and time, $R$ the gas constants and $T$ the absolute temperature.

Next, using the results as shown in Fig. 4, the chemical diffusion coefficient $D_{\varepsilon}$ of $\mathrm{Al}$ contained in Fe was calculated by the Matano method(33).

Let the direction of diffusion be the $x$-direction. The origin $x=0$ should be chosen so as to satisfy the relation

$$
\int_{c_{s}}^{C_{0}} x d c=\int_{c_{b}}^{0} x d c
$$

or

$$
\int_{0}^{c_{s}} x d c=0 \text {, }
$$

where $C_{o}$ and $C_{s}$ are $\mathrm{Al}$ concentration at the Matano interface and surface, respectively. Let us assume the original surface at $t=0$ to be at $x=-a$, the position of the surface at the time $t$ to be at $x=-b(t)$, and Al concentration $C$ on the side plane at $x=-b(t)$ to be constant.

The bounbary condition is

and

$$
C=C_{s} \quad \text { for } \quad x=-b,
$$

In this case, the solution $C(x, t)$ of the Fick equation

$$
\frac{\partial c}{\partial t}=\frac{\partial}{\partial x}\left(D_{c} \frac{\partial c}{\partial x}\right)
$$

is the only function of $\lambda=x / \sqrt{t}$. In this equation

(31) L. C. Correa daSilva and R. F. Mehl : Trans. AIME, 175 (1948), 184.

(32) U. S. Landergern, Ph. D. Thesis, Carnegie Institute of Technology, Pittsburgh, Pennsylvania, May 1953.

(33) C. Matano : Japan J. Phys., 8 (1933), 109.
$D_{c}$ represents the chemical diffusion constant.

So the following equation is obtained by integrating the equation (2):

$$
D_{c}=-\frac{1}{2 t} \frac{d x}{d c} \int x d c
$$

The chemical diffusion constant $D_{c}$ was obtained by a numerical integration from the curve in Fig. 4 . The results are shown in Fig. 5. $D_{c}$ increases monotonously with the increase in the $\mathrm{Al}$ conentration.

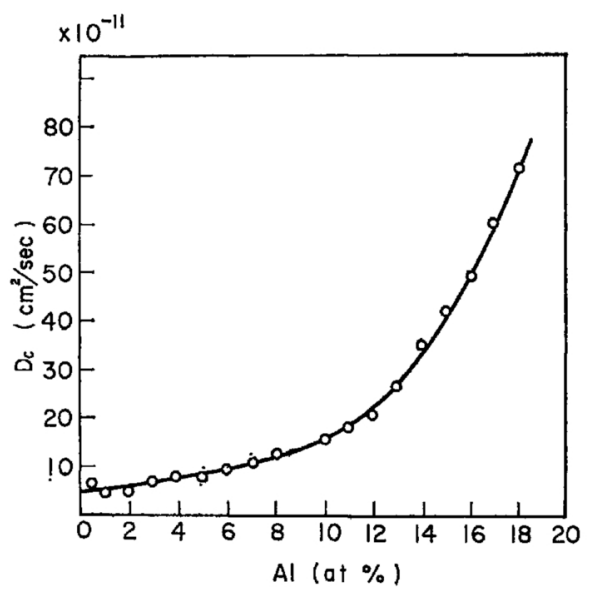

Fig. 5 Relation between chemical diffusion $D_{c}$ and Al concentration.

When the concentrations of $A$ and $B$ at the marker plane are constant, the ratio of the quantity $Q_{\mathrm{A}}$ of $\mathrm{A}$ atom diffused through the marker plane to the quantity $Q_{\mathrm{B}}$ of B atom diffused out through the same plane, satisfies the following relation ${ }^{(29)}$ :

$$
Q_{\mathrm{A}} / Q_{\mathrm{B}}=D_{\mathrm{A}} / D_{\mathrm{B}} \text {, }
$$

where $D_{\mathrm{A}}$ and $B_{\mathrm{B}}$ are as defined intrinsic diffusivity of $A$ atom and $B$ atom, respectively.

On the other hand, according to Darken (34), the velocity of the marker shift, $v_{m}$, is given by the following equation

$$
v_{m}=\left(D_{\mathrm{A}}-D_{\mathrm{B}}\right)\left(\frac{\partial C_{\mathrm{A}}}{\partial x}\right)_{m},
$$

where $\left(\partial C_{\mathrm{A}} / \partial x\right)_{m}$ is the concentration gradient at the marker's position. According to Balluffi ${ }^{(29)}$, in the diffusion between vapour and f.c.c. solid holds also the following Darken's equation for diffusion between solids :

$$
D_{c}=D_{\mathrm{A}} N_{\mathrm{B}}-D_{\mathrm{B}} N_{\mathrm{A}}
$$

where $N_{\mathrm{A}}$ and $N_{\mathrm{B}}$ are the concentration of $\mathrm{A}$ and B atoms, respectively. Assuming that the relation (6) is kept in the present b.c.c. case, then $D_{\mathrm{A} 1}$ and $D_{\mathrm{Fe}}$ are obtained from equations (6) and (4) or (5).

From equations (4) and (6),

$$
\begin{aligned}
& D_{\mathrm{A} 1}=8.6 \times 10^{-10} \mathrm{~cm}^{2} \cdot \mathrm{sec}^{-1}, \\
& D_{\mathrm{Fe}}=4.4 \times 10^{-10} \mathrm{~cm}^{2} \cdot \mathrm{sec}^{-1} .
\end{aligned}
$$

Putting the following values obtained from the curve in Fig. 4

$$
\begin{aligned}
Q_{\mathrm{Al}} / Q_{\mathrm{Fe}} & =5.61, \\
t & =529 \mathrm{hr},
\end{aligned}
$$

(34) L. S. Darken: Trans. AIME, 175 (1948), 184. 


$$
\begin{aligned}
x_{m} & =2 \times 10^{-3} \mathrm{~cm}, \\
\left(\partial C_{\mathrm{Ai}} / \partial x\right)_{m} & =2.5,
\end{aligned}
$$

and $D_{\mathrm{C}}=82 \times 10^{-11} \mathrm{~cm}^{2} \cdot \mathrm{sec}^{-1}$ (at the marker's position) into equations (6) and (5), we have

$$
\begin{aligned}
& D_{\mathrm{A} 1}=9.7 \times 10^{-10} \mathrm{~cm}^{2} \cdot \mathrm{sec}^{-1}, \\
& D_{\mathrm{Fe}}=1.73 \times 10^{-10} \mathrm{~cm}^{2} \cdot \mathrm{sec}^{-1} .
\end{aligned}
$$

It may be said that the values of $D_{\mathrm{A} 1}$ and $D_{\mathrm{Fe}}$ obtained by the two different methods are in good agreement with each other.

In observing the Kirkendall effect between vapour and solid phases, any porosity was not observed in the experiment of the $\mathrm{Zn}-\alpha$ brass system ${ }^{(29)}$ and the $\mathrm{Ni}$ $\mathrm{Cu}$ system $^{(29)}$, but in the $\mathrm{Ag}-\mathrm{Au}$ system $^{(29)}$ it was observed as in the solid-solid cases. In the present experiment, no porosity was observed around the marker. Sometimes, porosity is taken up as evidence of the vacancy mechanism of the Kirkendall effect, although it dose not always appear even in solid-solid cases as in the case of pure $\mathrm{Cr}$ and $\mathrm{Fe}-\mathrm{Cr}$ alloys.
In the present case of $\mathrm{Fe}_{3} \mathrm{Al}-\alpha \mathrm{Fe}$, mass flow is clearly observed in the b.c.c. lattice, and a similar evidence for mass flow in b.c.c. has been found in many of the studies stated above. Therefore, it may be concluded that the diffusion in the b.c.c. lattice does not take place by the ring diffusion mechanism suggested by Zener ${ }^{(20)}$ and LeClaire ${ }^{(21)}$.

\section{Acknowledgement}

The author would like to express his sincere thanks to Professer T. Hirone of Tohoku University, Dr. N. Kunitomi of Japan Atomic Energy Research Institute and Dr. T. Suzuoka of Tohoku University for valuable discussions. The author also wishes to express his thanks to Dr. J. Mizuno of Sumitomo Atomic Energy Laboratory for X-ray analysis. This work was supported by the Scientific Research Fund granted by the Ministry of Education. 